\title{
ALLOCATION OF STRUCTURAL FUNDS BEFORE AND AFTER THE BREXIT: AN EXERCISE IN THE ECONOMICS OF CAKE-SHARING
}

\author{
Wim Heijman \\ Wageningen University, The Netherlands \\ e-mail:wim.heijman@wur.nl
}

\begin{abstract}
What impact has the Brexit on the allocation of money from the structural funds? As the UK is a net contributor to the EU budget, the budget for Structural and Cohesion Policy will shrink. This will have an impact on the allocations of the structural funds to the remaining members of the EU. In order to estimate the allocation of the structural funds to the remaining EU members an allocation model is developed in this article. It appears that the model results do not only show the sharing of the cake, but also the size of it.
\end{abstract}

Keywords: EU Budget, Structural and Cohesion Policy, Allocation of structural funds, Economics of cake-sharing (JEL Code: F00, Q00)

\section{INTRODUCTION}

EU's budget contains two major parts: The Common Agricultural Policy (CAP) and the regional and structural policy dealing with the allocation of the Structural Funds. These funds include: European Regional Development Fund, European Social Fund, Cohesion Fund, European Solidarity Fund, Instrument for Pre-Accession (IPA). The European Agricultural Fund for Rural Development is also an instrument of structural policy but is an instrument of the CAP $\left(2^{\text {nd }}\right.$ pillar $)$. Roughly the break-down of the EU-budget of $€ 1020$ Billion for the 7-years period 2014-2020 is as follows (Table 1):

Table 1: EU Budget 2014-2020

\begin{tabular}{|l|r|r|}
\hline Item & Billions of Euro & $\%$ \\
\hline CAP & 410 & 40 \\
\hline $\begin{array}{l}\text { Regional and Cohesion } \\
\text { Policy }\end{array}$ & 350 & 34 \\
\hline Other & 260 & 26 \\
\hline Total & 1020 & 100 \\
\hline \multicolumn{2}{c}{ Source: EC (2017) }
\end{tabular}

It is foreseen that The Rural Development Fund will spend $€ 95$ Billion in the period

indicated. The British contribution to the total budget is estimated at $13.5 \%$ of the total amount which equals around $€ 138$ Billion (Statista, 2017). In the remainder of this article I aim to estimate the financial consequences of the Brexit for the allocation of the structural funds. First I will indicate the distribution in the 7-years period 2014-2020. Then I will estimate what would have happened if the funds would have been allocated in the situation the UK would have left before 2014. Finally I will develop an allocation model to estimate the budget and allocation of the funds for the period 2020-2026.

\section{SHARING THE CAKE AFTER BREXIT}

Assume that the British contribution to the budget $B$ of the structural funds had been withdrawn for the period 20142020 and that the UK-share suk in the allocation of the funds had to be reallocated over the remaining member states. The new share $S_{i}^{n}$ of each of these member states would become:

$$
s_{i}^{n}=\frac{s_{i}}{1-s_{u k}},
$$

In which si is the member state's original share in allocation of structural funds. Further the new budget $B n$, without the British contribution, equals:

$$
B_{n}=\left(1-b_{u k}\right) B,
$$

In which buk represents the share of the British contribution in the total budget $B$ of the structural funds. The new allocation $A_{i}^{n}$ to each of the remaining member states can now be computed as: 


$$
A_{i}^{n}=\frac{\left(1-b_{u k}\right)}{\left(1-s_{u k}\right)} S_{i} B=\frac{\left(1-b_{u k}\right)}{\left(1-s_{u k}\right)} A_{i},
$$

With $A i$ for the original allocation from the structural funds to a member state. The conclusion is that the remaining member states receive a larger share of a smaller cake. The net outcome of this depends on the values of buk and suk. If $b u k=s u k$, the new allocation $A_{i}^{n}$ will be equal to the original allocation $A_{i}$; if buk <suk, $A_{i}^{n}>A i$; if buk $<\operatorname{suk}, A_{i}^{n}<$ $A_{i}$. Because the British share buk in the budget $B$ equals $13.5 \%$ and the British share suk in the allocation equals $3.14 \%$, the remaining country's allocation $A_{i}^{n}$ will be reduced by approximately $10.7 \%$. Figure 2 presents this situation.

Figure 1: Allocations for the period 2014-2020, with the UK (left bars) and without the UK (right bars).

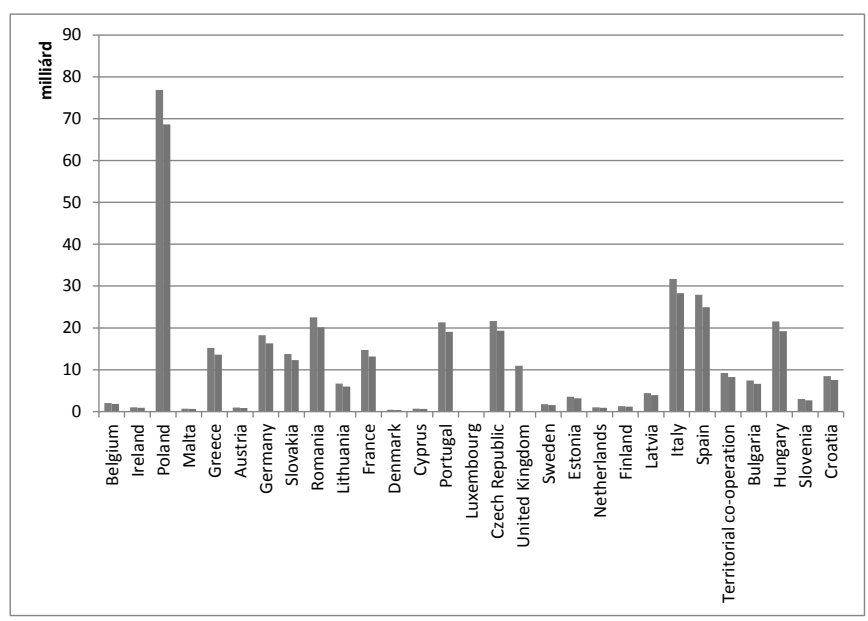

Source: EC (2015), http://ec.europa.eu/regional_policy/en/funding/ available-budget/, own calculations.

It appears that especially Poland benefits from the present allocation. In the period indicated Poland is planned to receive around 2.5 times as much as Italy, which is the number 2 in the ranking. For a country like Hungary Brexit before 2014 would have meant a decrease of the present budget from 21.5 billion to 19.2 Billion Euro for the period 2014-2020.

Taking only into account Brexit with respect to the forecast of the budget and budget allocation for the period 2021-2027 is useful for a first approach. For a more sophisticated estimation of the budget and its allocation over the member states a model is needed.

\section{AN ALLOCATION MODEL}

In order to estimate how the structural funds could be allocated after 2020 I developed the following simple model (See also Heijman and Koch, 2011):

$$
A_{i}=\alpha e^{\beta s_{i}} P_{i}^{\gamma} I_{i}^{\delta},
$$

with $S_{i}$ for the per member country share of the NUTS-2
Regions with a per capita GDP below 75\% of the EU average; $P_{i}$ for the total population per country and $I_{i}$ for the per capita GDP per country. The difference between Heijman and Koch's model is the introduction of the variable $S .1$ The idea behind it is that NUTS-2 regions with a GDP per head below 75\% of the EU-average are likely to be eligible for EU-funding of regional projects. The introduction of the variable in the model will probably lead to a higher percentage of the variance explained $\left(R^{2}\right)$ compared to its original version, which include only the variables $P$ and $I$. The model will be estimated in its linear transformation:

$$
\ln A_{i}=\ln \alpha+\beta S_{i}+\gamma \ln P_{i}+\delta \ln I_{i},
$$

in which $\gamma$ and $\delta$ are elasticities. The data used for this model are presented in Table 2 .

Table 2: Share Si of under 75\% of the average $E U$ GDP regions (NUTS-2), total population and GDP per capita per member state

\begin{tabular}{|l|l|l|l|}
\hline Member State & $\mathrm{S}_{\mathrm{i}}$ & Population (adj.) & $\begin{array}{l}\text { GDP/ } \\
\text { capita }\end{array}$ \\
\hline Belgium & 0.4 & 12.3428608 & 44300 \\
\hline Ireland & 0.5 & 5.4964302 & 68574 \\
\hline Poland & 0.9375 & 32.6892954 & 12271 \\
\hline Malta & 1 & 0.3857144 & 21272 \\
\hline Greece & 0.846154 & 8.8714312 & 34832 \\
\hline Austria & 0.111111 & 9.3535742 & 44600 \\
\hline Germany & 0.2 & 78.107166 & 46352 \\
\hline Slovakia & 1 & 4.7250014 & 18440 \\
\hline Romania & 0.875 & 13.4035754 & 9615 \\
\hline Lithuania & 1 & 2.3142864 & 13674 \\
\hline France & 0.692308 & 69.7178778 & 49489 \\
\hline Denmark & 0.2 & 6.0750018 & 56500 \\
\hline Cyprus & 0 & 1.0607146 & 20600 \\
\hline Portugal & 0.714286 & 8.7750026 & 23930 \\
\hline Luxembourg & 0 & 0.6750002 & 118538 \\
\hline Czech Republic & 0.875 & 10.7035746 & 19100 \\
\hline United Kingdom & 0.459459 & 74.250022 & 45731 \\
\hline Sweden & 0 & 12.1500036 & 56703 \\
\hline Estonia & 1 & 1.1571432 & 14600 \\
\hline Netherlands & 0.083333 & 17.4535766 & 54640 \\
\hline Finland & 0.2 & 5.6892874 & 53616 \\
\hline Latvia & 1 & 1.446429 & 15097 \\
\hline Italy & 0.428571 & 61.232161 & 41259 \\
\hline Spain & 0.473684 & 38.3785828 & 41565 \\
\hline Territorial Co-operation & 0 & 18.3875 & 3100 \\
\hline Bulgaria & 1 & 5.5928588 & 6300 \\
\hline Hungary & 0.857143 & 9.0642884 & 13231 \\
\hline Slovenia & 1 & 1.928572 & 28398 \\
\hline Croatia & 3.375001 & 13400 \\
\hline & & \\
\hline
\end{tabular}

Source: StatisticsTimes (2017), Eurostat (2016).

1 The reason why I use $e^{\beta s_{\text {iinstead of }}} \beta S_{i \text { is that in the linear }}$ transformation I make use of natural logarithms. If $\mathrm{s}_{\mathrm{i}}=0$, which is the case in some countries, the natural logarithm $\ln s_{i}$ does not exist. 
In order to make the make the model work I have allocated a population of around 18.4 million people to the extraterritorial region, which is the average number of inhabitants of all the present member states. This is about $3.6 \%$ of the total EU population. This percentage is used to reduce the population numbers of all the member states. Further we assume that the people populating the extra territorial region are producing $€ 31,000$ per capita which is about the EU average GDP per capita.

\section{RESULTS}

The linear regression procedure gave the following results ( $t$-values in brackets):

(1) $\ln A_{i}=\underset{(10.42)}{29.17}+\underset{(3.69)}{1.67} S_{i}+\underset{(10.94)}{0.93} \ln P_{i}-\underset{(-3.75)}{0.95} \ln I_{i}$,

$$
R^{2}=0.8
$$

The constant and the variables involved are all highly significant. If the model is estimated without $S$, the result is (with t-values in brackets):

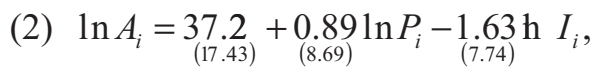

$$
R^{2}=0.81
$$

Apparently Model (1) explains a higher percentage of the variance than Model (2), the original model (Heijman and Koch, 2011).

On the basis of the model I am now able to estimate the allocation for the period 2021-2027 and compare it to the period 2014-2020 (Figure 3).

Figure 2: Model allocations of the structural funds for the period 2021-2027 (right bars) compared to the actual allocations for the period 2014-2020 (left bars), excluding the UK.

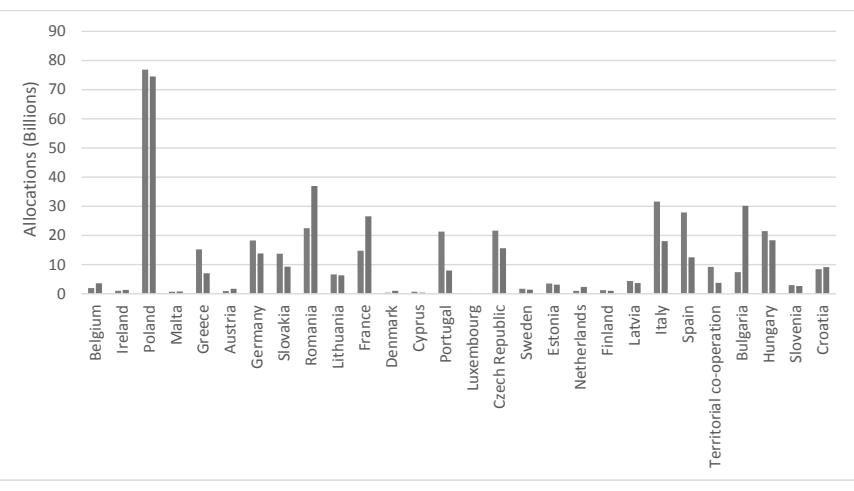

Model (1) allocates an amount of around $€ 315$ Billion for the period 2021-2027, which is around10\% less than the original budget of $€ 350$ Billion for the period 2014-2020. Roughly, this equals the budget cut necessary because of the Brexit.

It appears that especially the new member states Romania and Bulgaria may look forward to a higher allocation from the structural funds in the period 2021-2027, probably due to the relatively low absorption capacity in the present period. Central European member states like Poland, Czech Republic,
Slovakia and Hungary may expect some reduction. The model estimates a significant decrease in the allocation to South European members Italy, Spain, Greece and Portugal. Remarkably, also the Territorial Cooperation is expected to lose a substantial part of its subsidies. Germany will also lose part of it, where other West European members, like France may look forward to an increase.

\section{CONCLUSION}

Because at present the $\mathrm{UK}$ is a net payer to the $\mathrm{EU}$ budget, the budget will probably cut by more than $10 \%$ in the period 2021-2027 relative to the present period. From around $€ 350$ Billion the budget for Structural and Cohesion Policy will be reduced to around $€ 315$ Billion. In the first approach the budget for the remaining members was cut by this percentage. However, it is not only the Brexit that will influence the budget and the budget allocation. In order to find out the consequences for the remaining members in a more sophisticated way an allocation model was developed, based upon three variables: share of low income NUTS-2 regions on national level, total population and GDP per head.

This model was used not only to estimate the 'cakesharing', but also the total size of the 'cake'. On the basis of the model it could be estimated that the necessary budget for 2021-2027 would be $10 \%$ less than in the previous period, which is in line with the financial consequences of Brexit. Further, especially Romania and Bulgaria would receive larger allocations from the funds, where the allocations towards South Europe would be significantly less. A number of East European members and Germany would receive smaller amounts, where France and other West European members would receive larger allocations.

\section{REFERENCES}

EC (2015), http://ec.europa.eu/regional_policy/en/funding/available-budget/

EC (2017). http://ec.europa.eu/budget/mff/preallocations/index_ en.cfm

Eurostat (2016). http://ec.europa.eu/eurostat/statistics-explained/ index.php/GDP_at_regional_level

Heijman W. and T. Koch, 2011. The allocation of financial resources of the EU Structural Funds and Cohesion Fund during the period 2007-2013. Agricultural Economics (Czech Academy of Agricultural Sciences), Vol. 57, pp. 49-56.

Statista (2017). https://www.statista.com/statistics/316691/european-union-eu-budget-share-of-contributions/

StatisticsTimes (2017). http://statisticstimes.com/economy/european-countries-by-gdp-per-capita.php 
